\title{
Metabolic adaptation in small for gestational age infants
}

\author{
J M Hawdon, M P Ward Platt
}

\begin{abstract}
Hypoglycaemia has long been recognised as a feature of the failure of metabolic adaptation in infants who are small for gestational age (SGA). This study examined the process of metabolic adaptation by measuring, longitudinally, the concentrations of metabolic fuels and substrates in 33 SGA infants in the first postnatal week, and relating these to cross sectional data in 218 infants of appropriate weight for gestational age (AGA).

SGA term infants had higher mean blood lactate concentrations than AGA term infants at delivery $(2.98 v$ $2.10 \mathrm{mmol} / \mathrm{l})$ and in the first few postnatal hours (3.05 v 1.91 mmol/1). Subsequently, although there were no differences in blood glucose concentrations, SGA term infants had lower mean ketone body concentrations (for example day 2: 0.07 $v$ $0.41 \mathrm{mmol} / \mathrm{l}$ ), and failed to mount a ketogenic response to low blood glucose concentrations. At birth, SGA preterm infants had lower mean blood glucose concentrations than AGA preterm infants (3.17 v $4.16 \mathrm{mmol} / \mathrm{l})$, but there were few postnatal metabolic differences between the two groups. Mean blood glucose concentrations did not differ between AGA and SGA preterm infants. For variables that differed between the groups, multiple regression analysis suggested that both the degree and asymmetry of growth retardation were related to the severity of the metabolic abnormalities.

These data suggest that, although there are early metabolic differences between SGA and AGA infants, it is possible that current clinical management is effective in preventing subsequent hypoglycaemia. This is important because of the failure of SGA infants to mount a ketogenic response.
\end{abstract}

\section{(Arch Dis Child 1993;68:262-268)}

Department of Child Health, University of Newcastle upon Tyne J M Hawdon

M P Ward Platt

Correspondence to: Dr J M Hawdon, Institute of Child Health, Royal Liverpool Children's Hospital Alder Hey, Eaton Road,

Liverpool L12 2AP.

Accepted 25 August 1992
It is now known that some metab be evident antenatally, such as by hypoxia, acidosis, hyperlactataemia, and hypoglycaemia. ${ }^{7-10}$ The postnatal metabolic problems of SGA infants have been reviewed by Usher, ${ }^{11}$ Mestyan, ${ }^{12}$ Jones and Roberton, ${ }^{13}$ and Hay, ${ }^{14}$ who suggested that the increased risk of hypoglycaemia may be secondary to increased glucose utilisation (partly because of the disproportionately high brain weight), hormonal or enzymatic imbalance resulting in failure of gluconeogenesis, reduced stores of fat and glycogen, and inability to mobilise fat stores and oxidise fatty acids to ketone bodies.

These studies of postnatal metabolic events were performed at a time when intravenous and enteral feeding policies were less liberal than at present. The adequate provision of enteral and parenteral energy may counteract the metabolic difficulties of SGA infants so that hypoglycaemia is not seen.

The purpose of the present study was to investigate whether SGA infants exhibited any differences in metabolic adaptation compared with infants who were of appropriate weight for gestational age (AGA) when exposed to present feeding policies (which encourage early and frequent milk feeds and intravenous glucose supplementation if adequate enteral feed volumes are not tolerated). We compared the metabolic changes seen after birth in a group of healthy AGA infants and a group of SGA infants to investigate whether failure of metabolic adaptation was seen in the SGA group, first, at birth, and second, after the commencement of enteral and intravenous feeding, and whether hypoglycaemia was the only biochemical evidence of failure of metabolic adaptation.

\section{Subjects and methods}

Thirty three singleton infants, of mixed gestational age, who were suspected antenatally of being SGA, and who had birth weights below the 10th centile, were studied longitudinally. Prefeed blood samples were taken once a day for the first postnatal week (SGA infants). Reference data were obtained from cross sectional studies of 62 preterm and 156 term singleton infants, less than 1 week old, who had birth weights above the 10th centile (AGA infants) ${ }^{15}$. Infants were excluded if they were non-white, had major congenital abnormalities, or were clinically unstable at the time of study, for example, if they were hypoxic, acidotic, or hypotensive.

Conditions during blood sampling, sampling techniques, and biochemical analyses were as described previously. ${ }^{15}$

Details of maternal obstetric history, 
presence of fetal distress (thick meconium in the liquor amnii, or cardiotocography evidence - loss of beat to beat variability or type 11 decelerations), and method of delivery were recorded. Maternal obstetric problems included hypertension, prolonged rupture of membranes, haemorrhage and infection during pregnancy, and mechanical problems at delivery. Each infant's birth weight, head circumference, and mid-arm circumference were recorded on the day of birth. A birthweight SD score was calculated, which represented the number of SDs by which the infant's birth weight differed from the mean for gestational age. Birthweight centile charts used were those previously derived from Newcastle births. ${ }^{16}$ Similarly, SD scores for mid-arm circumference:head circumference ratio (MAC:HC) were found using data obtained by Sasanow et al. ${ }^{17}$

Data were analysed using the SPSS-X package. Pearson correlation coefficients were used to define interrelationships between substrates, and $\chi^{2}$ and $t$ tests were used to compare groups of infants. Because aspects of metabolic adaptation have previously been found to differ for term and preterm infants, ${ }^{15}$ these groups underwent separate analyses. Total gluconeogenic substrate, ketone body, and non-esterified fatty acid concentrations had $\log$ normal distributions, therefore $\log _{10}$ values for these concentrations were used for statistical analysis, and the means presented are geometric means. Multiple regression analysis was used to identify factors associated with any metabolic abnormalities. To avoid the confounding effect of repeated values for the SGA group, which was studied longitudinally, multiple regression analysis was performed for values taken on individual postnatal days.

Ethical approval for the study was granted by the ethics committee of Newcastle Health Authority. Informed consent was obtained from parents for the inclusion of each baby in the study, and as far as possible sampling was coordinated with clinically necessary tests.

\section{Results \\ Table 1 shows the magnitude of differences between the SGA and AGA groups. The only parameter for which a significant difference did not exist was head circumference for the preterm group. Considering SGA and AGA infants together, there was a highly significant relationship between birthweight SD score and MAC:HC SD score (term infants: $r=0.70, \mathrm{p}<0.001$; preterm infants: $r=0.74$, $\mathrm{p}<0.001$; all infants: $r=0.71, \mathrm{p}<0.001)$. This}

suggests that the SGA infants studied had true intrauterine grown retardation, with sparing of head growth. For preterm infants only, there were significant relationships between maternal height and both birthweight and MAC:HC SD scores $(r=0.28, \mathrm{p}<0.05$; $r=0.35, \mathrm{p}<0.01$, respectively), but this was not found for term infants.

Maternal, obstetric, and perinatal characteristics are summarised in table 2. Few differences were found between the groups, but term SGA infants were more likely than term AGA infants to have had clinical evidence of fetal distress. However, cord $\mathrm{pH}$ values did not differ between the groups. Although there was a strong correlation between cord $\mathrm{pH}$ and lactate concentrations for all infants $(r=-0.50, \mathrm{p}<0.001)$, among all the infants studied (AGA and SGA), those with fetal distress did not have significantly lower cord $\mathrm{pH}$ than those without fetal distress, but cord lactate concentration was significantly higher (3.55 v $2.29 \mathrm{mmol} / \mathrm{l}$, $\mathrm{p}<0 \cdot 01$ ) (fig 1 ).

Table 2 Maternal, obstetric, and perinatal factors

\begin{tabular}{|c|c|c|c|c|}
\hline & \multicolumn{2}{|l|}{ Term } & \multicolumn{2}{|l|}{ Preterm } \\
\hline & $\begin{array}{l}S G A \\
(n=22)\end{array}$ & $\begin{array}{l}A G A \\
(n=156)\end{array}$ & $\begin{array}{l}S G A \\
(n=11)\end{array}$ & $\begin{array}{l}A G A \\
(n=62)\end{array}$ \\
\hline $\begin{array}{l}\text { Mean mother's } \\
\text { height }(\mathrm{cm}) \\
\text { Mothers smoking (\%) }\end{array}$ & $\begin{array}{l}160 \\
8(36)\end{array}$ & $\begin{array}{l}159 \\
40(26)\end{array}$ & $\begin{array}{l}159 \\
7(64)\end{array}$ & $\begin{array}{l}162 \\
27(44)\end{array}$ \\
\hline $\begin{array}{l}\text { Problems in } \\
\text { pregnancy (\%) }\end{array}$ & & & & \\
\hline (other than SGA) & $7(32)$ & $30(19)$ & $10(91)$ & $44(71)$ \\
\hline Problems with labour (\% & $1(5)$ & $6(4)$ & $0(0)$ & $12(19)$ \\
\hline $\begin{array}{l}\text { Delivery (\%): } \\
\text { Vaginal:normal }\end{array}$ & & & & \\
\hline $\begin{array}{l}\text { Vaginal:normal } \\
\text { Caesarean section }\end{array}$ & $\begin{array}{l}13(59) \\
6(27)\end{array}$ & $\begin{array}{l}70(45) \\
86(55)\end{array}$ & $\begin{array}{l}2(18) \\
8(73)\end{array}$ & $\begin{array}{l}36(58) \dagger \\
26(42) t\end{array}$ \\
\hline & 3 (14) & & $1(9)$ & $0(0)$ \\
\hline Fetal distress (\%) & $9(41)$ & $19(12) * *$ & $4(36)$ & $16(26)$ \\
\hline $\begin{array}{l}\text { Cord pH } \\
\text { IPPV requir }\end{array}$ & 7. & & & \\
\hline birth (\%) & $3(14)$ & $7(4)$ & $5(45)$ & $35(56)$ \\
\hline
\end{tabular}

IPPV=intermittent positive pressure ventilation.

$\chi^{2}$ significant differences between SGA and AGA infants; $* *$ p $<0.01 ; \dagger$ preterm infants, vaginal delivery $v$ caesarean section: $\mathrm{p}<0.05$.

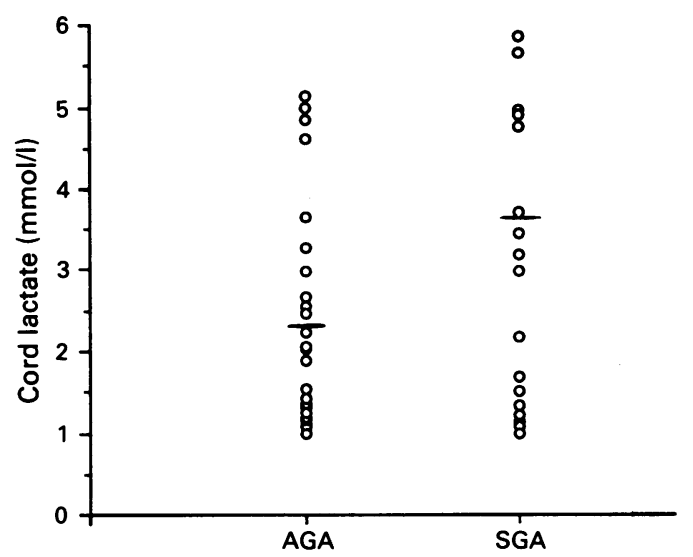

Figure 1 Distribution of cord lactate concentrations for $A G A$ and $S G A$ infants.

Table 1 Demographic details of infants studied

\begin{tabular}{|c|c|c|c|c|c|c|}
\hline & \multicolumn{3}{|l|}{ Term } & \multicolumn{3}{|l|}{ Preterm } \\
\hline & $S G A(n=22)$ & $A G A(n=156)$ & $S E$ difference & $S G A(n=11)$ & $A G A(n=62)$ & $S E$ difference \\
\hline $\begin{array}{l}\text { Median (range) gestation in weeks } \\
M \cdot F\end{array}$ & $38(37-40)$ & $39(37-42)$ & & $34(28-35)$ & $31(25-36)$ & \\
\hline Mean (range) birth weight in $\mathrm{g}$ & $2178(1700-2600)$ & $3410(2575-4565)$ & 61 & $1320(668-1870)$ & $1726(830-3203)$ & 144 \\
\hline Mean SD score & -2.50 & 0.45 & $0 \cdot 16$ & -3.41 & 0.04 & 0.27 \\
\hline Mean $\mathrm{HC} / \mathrm{cm}$ & $32 \cdot 0$ & $35 \cdot 0$ & $0 \cdot 2$ & $28 \cdot 4$ & $29 \cdot 5$ & $0 \cdot 8$ \\
\hline Mean $\mathrm{MAC} / \mathrm{cm}$ & $8 \cdot 4$ & $10 \cdot 7$ & $0 \cdot 2$ & $6 \cdot 6$ & $7 \cdot 5$ & $0 \cdot 3$ \\
\hline Mean MAC:HC & $0 \cdot 26$ & 0.31 & 0.01 & $0 \cdot 23$ & $0 \cdot 25$ & 0.01 \\
\hline Mean MAC:HC SD score & -1.52 & $1 \cdot 48$ & 0.42 & $-2 \cdot 31$ & $0 \cdot 70$ & 0.57 \\
\hline
\end{tabular}


Significantly more preterm SGA infants than preterm AGA infants were born by caesarean section, reflecting a high degree of obstetric concern.

For all infants, there were significantly lower mean birth weight SD and MAC:HC SD scores for infants of smoking mothers than for infants whose mothers did not smoke $(-0.34 v 0.08, \mathrm{p}<0.05 ; 0.52 v 1.10, \mathrm{p}<0.05)$.

In the first few postnatal days, term SGA infants received more frequent feeds, and higher intakes of milk, intravenous glucose and energy than AGA infants, reflecting the feed and fluid regimens presently in use for such babies. On day 2, preterm SGA infants had higher intravenous glucose intakes than preterm AGA infants, and on day 5, SGA babies had higher milk intakes than AGA babies. These differences are shown in table 3.

Significant differences between the groups, in terms of blood metabolite concentrations are shown in table 4 . Figure 2 demonstrates

Table 3 Mean between feed interval and daily intakes of energy, milk, and intravenous $10 \%$ glucose that differ significantly $(p<0.05)$ between $S G A$ and $A G A$ infants

\begin{tabular}{|c|c|c|c|c|c|c|}
\hline & \multicolumn{3}{|l|}{ Term } & \multicolumn{3}{|l|}{ Preterm } \\
\hline & $\begin{array}{l}S G A \\
(n=22)\end{array}$ & $\begin{array}{l}A G A \\
(n=156)\end{array}$ & $\begin{array}{l}S E \\
\text { difference }\end{array}$ & $\begin{array}{l}S G A \\
(n=11)\end{array}$ & $\begin{array}{l}A G A \\
(n=62)\end{array}$ & $\begin{array}{l}S E \\
\text { difference }\end{array}$ \\
\hline 12-24 hours: & & & & & & \\
\hline $\begin{array}{l}\text { Intravenous glucose }(\mathrm{ml} / \mathrm{kg} / \text { day }) \\
\text { Day } 2 \text {. }\end{array}$ & 29 & 0 & 10 & & & \\
\hline Day 2: & & & & & & \\
\hline Interval (min) & 153 & 252 & 20 & & & \\
\hline Milk (ml/kg/day) & 126 & 66 & 15 & & & \\
\hline Energy $(\mathrm{kJ} / \mathrm{kg} / \mathrm{day})$ & 443 & 234 & 50 & & & \\
\hline Intravenous glucose $(\mathrm{ml} / \mathrm{kg} /$ day $)$ & & & & 114 & 70 & 14 \\
\hline Day 3: & & & & & & \\
\hline Interval (min) & 176 & 235 & 22 & & & \\
\hline Energy (kJ/kg/day) & 489 & 368 & 54 & & & \\
\hline Day 4: & & & & & & \\
\hline Interval (min) & 172 & 217 & 20 & & & \\
\hline $\begin{array}{l}\text { Day 5: } \\
\text { Milk (ml/kg/day) }\end{array}$ & & & & 104 & 49 & 25 \\
\hline
\end{tabular}

Table 4 Mean blood concentrations of intermediary metabolites ( $m m o l l)$ that differ significantly $(p<0.05)$ between $S G A$ and $A G A$ infants

\begin{tabular}{|c|c|c|c|c|c|c|}
\hline & \multicolumn{3}{|l|}{ Term } & \multicolumn{3}{|l|}{ Preterm } \\
\hline & $\begin{array}{l}S G A \\
(n=22)\end{array}$ & $\begin{array}{l}A G A \\
(n=156)\end{array}$ & $\begin{array}{l}S E \\
\text { difference }\end{array}$ & $\begin{array}{l}S G A \\
(n=11)\end{array}$ & $\begin{array}{l}A G A \\
(n=62)\end{array}$ & $\begin{array}{l}S E \\
\text { difference }\end{array}$ \\
\hline \multicolumn{7}{|l|}{ Cord: } \\
\hline Glucose & & & & $3 \cdot 17$ & $4 \cdot 16$ & $0 \cdot 38$ \\
\hline Lactate & $2 \cdot 98$ & $2 \cdot 10$ & $0 \cdot 46$ & & & \\
\hline Non-esterified fatty acid & $0 \cdot 21$ & $0 \cdot 10$ & $0 \cdot 10$ & & & \\
\hline \multicolumn{7}{|l|}{$<12$ hours: } \\
\hline Lactate & 3.05 & 1.91 & $0 \cdot 45$ & & & \\
\hline Total gluconeogenic substrate & $3 \cdot 23$ & $2 \cdot 37$ & 0.50 & & & \\
\hline Lactate:pyruvate ratio & 34 & 27 & & & & \\
\hline \multicolumn{7}{|l|}{ 12-24 hours: } \\
\hline Glycerol & $0 \cdot 13$ & $0 \cdot 20$ & 0.02 & & & \\
\hline Ketone body & 0.06 & $0 \cdot 24$ & $0 \cdot 01$ & & & \\
\hline \multicolumn{7}{|l|}{ Day 2: } \\
\hline Lactate & & & & $3 \cdot 19$ & 1.49 & 0.91 \\
\hline Pyruvate & 0.06 & 0.09 & 0.01 & $0 \cdot 10$ & 0.05 & 0.02 \\
\hline Glycerol & $0 \cdot 12$ & $0 \cdot 17$ & 0.01 & & & \\
\hline Total gluconeogenic substrate & $1 \cdot 78$ & $2 \cdot 22$ & $0 \cdot 24$ & $2 \cdot 94$ & $1 \cdot 60$ & 0.94 \\
\hline Ketone body & 0.07 & $0 \cdot 41$ & 0.01 & & & \\
\hline \multicolumn{7}{|l|}{ Day 3: } \\
\hline Glucose & $4 \cdot 03$ & $3 \cdot 39$ & $0 \cdot 24$ & & & \\
\hline Lactate & $1 \cdot 14$ & 1.46 & $0 \cdot 15$ & & & \\
\hline Pyruvate & 0.04 & 0.07 & 0.01 & & & \\
\hline Alanine & $0 \cdot 26$ & $0 \cdot 21$ & 0.02 & & & \\
\hline Glycerol & 0.09 & $0 \cdot 16$ & 0.01 & & & \\
\hline Total gluconeogenic substrate & 1.45 & 1.83 & $0 \cdot 17$ & & & \\
\hline Lactate:pyruvate ratio & 33 & 23 & 4 & & & \\
\hline Ketone body & 0.07 & $0 \cdot 43$ & 0.01 & & & \\
\hline Non-esterified fatty acid & $0 \cdot 19$ & $0 \cdot 47$ & 0.01 & & & \\
\hline \multicolumn{7}{|l|}{ Day 4: } \\
\hline Lactate & & & & $2 \cdot 12$ & $1 \cdot 43$ & 0.33 \\
\hline Pyruvate & & & & 0.07 & 0.05 & 0.01 \\
\hline \multicolumn{7}{|l|}{ Day 5: } \\
\hline Lactate & 0.97 & $1 \cdot 32$ & $0 \cdot 14$ & & & \\
\hline Pyruvate & 0.04 & 0.06 & 0.01 & & & \\
\hline Alanine & $0 \cdot 24$ & $0 \cdot 29$ & 0.02 & & & \\
\hline \multirow{2}{*}{\multicolumn{7}{|c|}{$\begin{array}{l}\text { 1 otal giuconeogenic substrate } \\
\text { Day 6: }\end{array}$}} \\
\hline & & & & & & \\
\hline Lactate & 1.04 & 1.68 & $0 \cdot 22$ & & & \\
\hline Pyruvate & 0.05 & 0.07 & 0.01 & & & \\
\hline Total gluconeogenic substrate & $1 \cdot 38$ & $2 \cdot 03$ & $0 \cdot 24$ & & & \\
\hline
\end{tabular}

the distribution of serial blood glucose concentrations. Compared with AGA infants, ${ }^{15}$ SGA infants (term or preterm) did not have lower mean blood glucose concentrations in the first postnatal week, and being SGA did not increase the risk of having low $(<2.6 \mathrm{mmol} / \mathrm{l})$ or high $(>10 \mathrm{mmol} / \mathrm{l})$ blood glucose concentrations after the first postnatal day. However, preterm SGA infants had significantly lower mean cord blood glucose concentration than AGA infants, 4/11 preterm SGA infants had cord glucose concentrations $<3 \mathrm{mmol} / \mathrm{l}$, while no AGA infant had a cord concentration this low. Multiple regression analysis with the following independent variables - birth weight, birthweight SD score, MAC:HC, MAC:HC SD score, and gestation - demonstrated that birthweight SD score was the only variable that correlated significantly with preterm babies' cord glucose concentrations $(\mathrm{B}=0.22, \mathrm{SE}$ $\mathrm{B}=0.09, \mathrm{p}=0.031$ ).

For term SGA infants, concentrations of lactate and other gluconeogenic precursors were high at birth and in the first six postnatal hours. Multiple regression analysis with the following independent variables - birth weight, birthweight SD score, MAC:HC, MAC:HC SD score, and gestation - demonstrated that the MAC:HC ratio was most significantly associated with these concentrations (cord lactate, $B=-0.29$, SE $B=0.08, p<0.001$; cord total gluconeogenic substrate, $B=-0.32$, SE $B=0.08, \quad p<0.001 ;<6$ hours lactate, $B=-0 \cdot 48$, SE $B=0.08, p<0.001 ;<6$ hours total gluconeogenic substrate, $B=-0.52, S E B=0.09$,
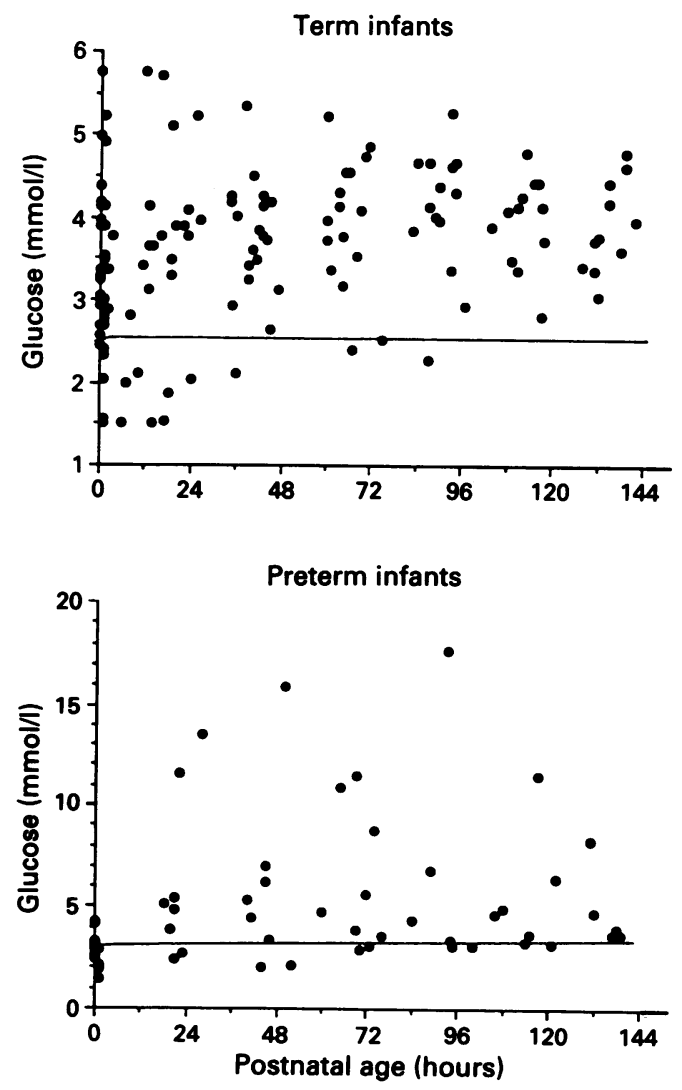

Figure 2 Distribution of blood glucose concentrations in term and preterm SGA infants. 
p<0.001) (fig 3). However, concentrations of lactate and total gluconeogenic substrate were persistently lower than those of AGA term infants from the second postnatal day. For preterm SGA infants, high blood lactate and total gluconeogenic substrate concentrations persisted up to the fourth postnatal day.

At birth, term SGA infants had higher concentrations of non-esterified fatty acids than AGA infants but similar concentrations of ketone bodies. Multiple regression analysis

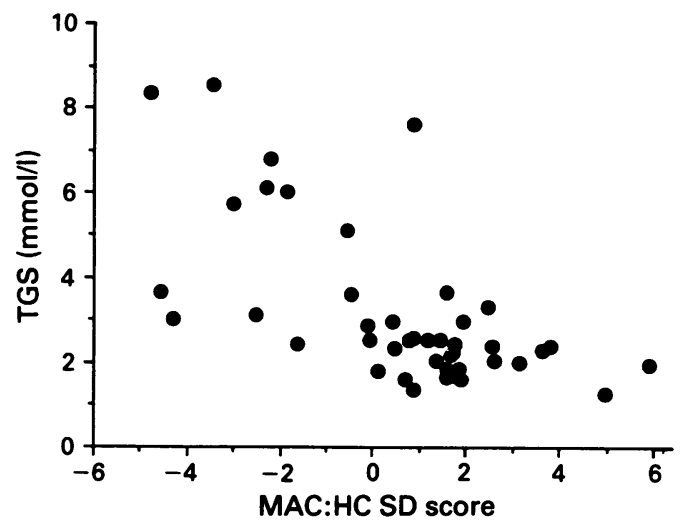

Figure 3 Relationship between total gluconeogenic substrate (TGS) concentration and MAC:HC SD score for term $A G A$ and $S G A$ infants $<6$ hours old.
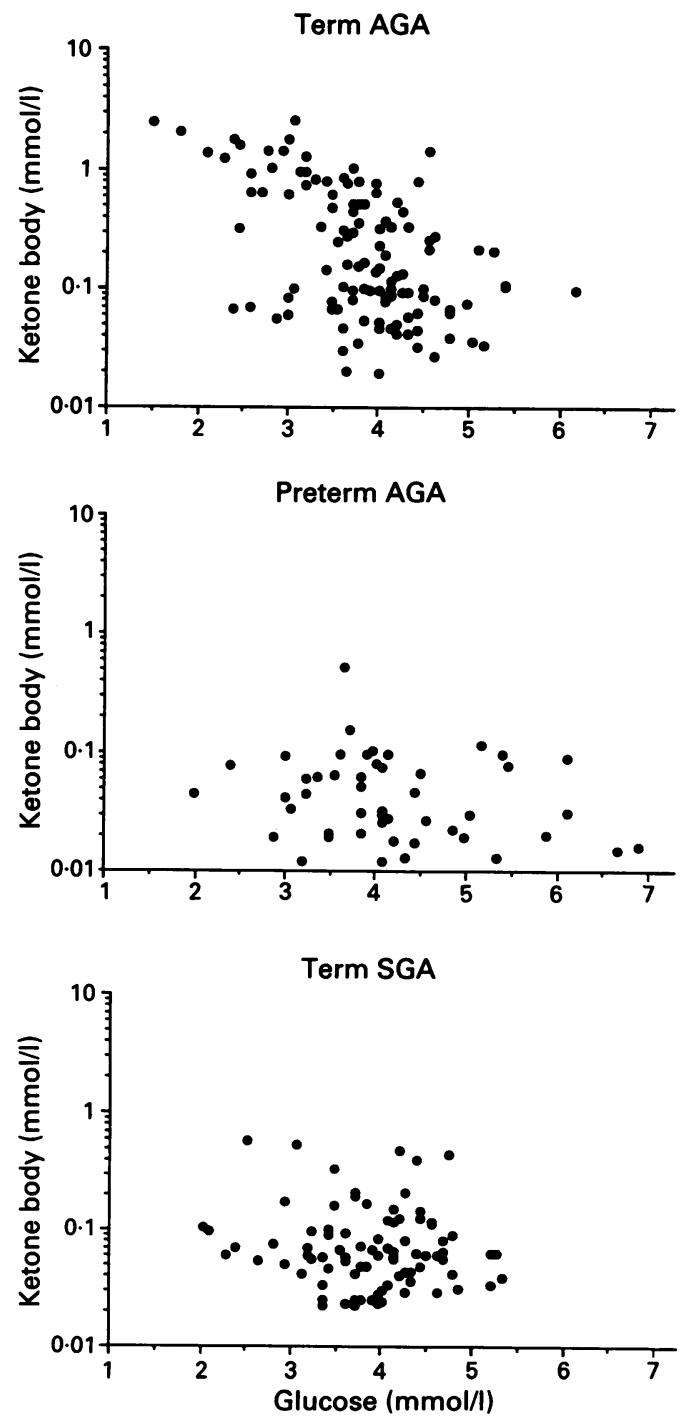

Figure 4 Relationship between ketone body and glucose concentrations in term and preterm $A G A$ and term $S G A$ infants. with the following independent variables birth weight, birthweight SD score, MAC:HC, MAC:HC SD score, and gestation - demonstrated that birthweight SD score was the only variable to be significantly associated with cord plasma non-esterified fatty acid concentration $(B=-0.08, S E B=0.03, p<0.01)$. For all term infants (AGA and SGA) on the first postnatal day, a positive correlation was found between ketone bodies and glucose concentrations $(r=0.35, \mathrm{p}<0.01)$. Multiple regression analysis confirmed that this relationship was independent of potentially confounding variables, namely, birth weight, birthweight SD score, MAC:HC, MAC:HC $\mathrm{SD}$ score, and gestation.

After 24 hours, concentrations of ketone bodies were lower for SGA infants, and there was no rise on the second and third postnatal days. On the second and third postnatal days an inverse relationship existed between ketone body and glucose concentrations for AGA term infants, ${ }^{15}$ but this relationship was not found for SGA term infants. Figure 4 shows the relationship between ketone bodies and glucose concentrations for preterm AGA, term AGA, and term SGA infants (more than 1 day old), and demonstrates that SGA term infants, like AGA preterm infants, failed to mount a ketone body response at low blood glucose concentrations. For all SGA and AGA term infants on day 2, independently of blood glucose concentration, daily milk feed volume, interval between feeds, size (birth weight, birthweight SD score, MAC:HC, MAC:HC SD score) and gestation, babies receiving the most energy, per unit body weight, had the lowest ketone body concentrations $(B=-5 \cdot 85$, SE $B=1 \cdot 78, p<0 \cdot 001$ ) (fig 5). However, on day 3, of these independent variables, MAC:HC SD score was the only variable to be significantly associated with non-esterified fatty acid concentration $(B=0 \cdot 12, S E B=0.05$, $p=0.026$, and birthweight SD score was the only variable to be significantly associated with ketone body concentration $(B=0 \cdot 16, S E$ $\mathrm{B}=0.06, \mathrm{p}=0.011$ ).

Like AGA preterm infants, SGA preterm infants had low ketone body concentrations throughout the first postnatal week. On day 2 there was a positive relationship between ketone body concentration and daily intake of enteral feed, which was independent of other

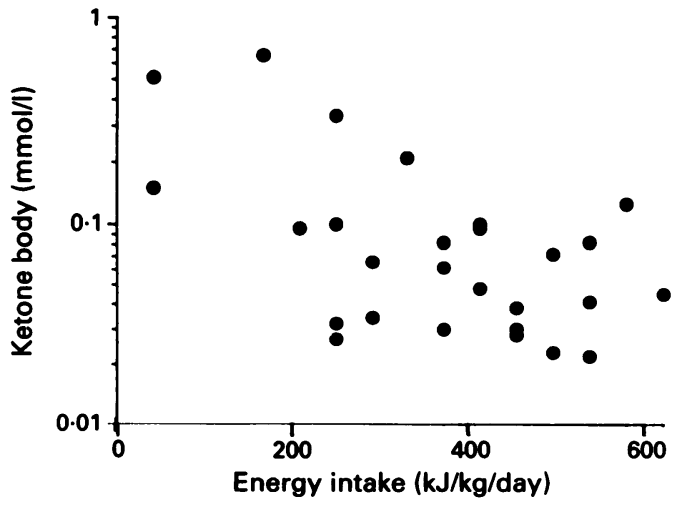

Figure 5 Relationship between energy intake and ketone body concentration for term $A G A$ and $S G A$ infants on the second postnatal day. 


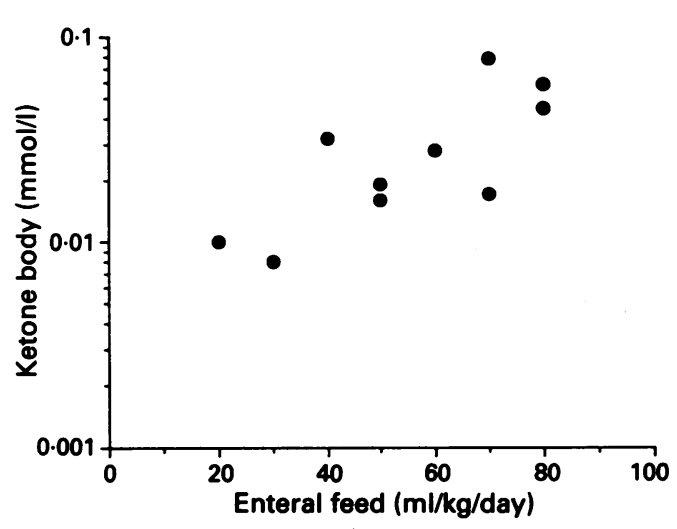

Figure 6 Relationship between ketone body concentration and enteral feed volume in preterm $A G A$ and $S G A$ infants on the second postnatal day.

variables, namely birth weight, birthweight SD score, MAC:HC, MAC:HC SD score, gestation, daily milk feed volume, interval between feeds, intravenous glucose intake, and total energy intake $(B=13 \cdot 08, S E B=3 \cdot 30$, $\mathrm{p}<0.01$ ) (fig 6).

\section{Discussion}

This study has demonstrated that SGA infants had concentrations of metabolic fuels in the early neonatal period that differed significantly, when compared with those of SGA infants, and these differences in metabolism were not confined to blood glucose concentrations. In clinical terms, these results suggest that adequate parenteral and enteral supplies of energy are critical to SGA babies and that early enteral feeding is beneficial. This lends support to the work of Aynsley-Green et al,${ }^{18}$ who proposed that early enteral feeding was associated with the maturation of the gut hormone response. In addition, the immaturity of the metabolic response to low blood glucose concentration, demonstrated in the present study, may help to explain the findings of Lucas et al that prolonged moderate hypoglycaemia had adverse effects on neurodevelopmental outcome. ${ }^{19}$

The exclusion of infants with other potentially confounding problems, the lack of differences in obstetric factors between groups, and the separate analysis of data from term and preterm infants have enabled the comparison of SGA and AGA groups. The fact that SGA infants had significantly lower MAC:HC ratios and MAC:HC SD scores suggests that asymmetrical growth retardation occurred, with sparing of head growth.

An increased incidence of fetal distress (demonstrated by cardiotocography and meconium staining of liquor) was found for term SGA infants, but not for preterm SGA infants, when compared with their AGA counterparts. This may have been because of the small number in the preterm SGA group, or because fetal distress was more common in AGA preterm infants, or it may reflect the number of SGA infants born by elective caesarean section, so pre-empting the occurrence of fetal distress. Although cord blood pH was not significantly different in SGA and AGA infants, there was other metabolic evidence that SGA infants had undergone some perinatal stress: term SGA infants had higher cord blood concentrations of nonesterified fatty acid and lactate, and these high levels persisted in the first six postnatal hours (see below). Although these infants mounted a poor ketogenic response to hypoglycaemia after the first postnatal day, the fact that, as for AGA infants, there was a positive relationship between glucose and ketone body concentrations on the first postnatal day suggests that SGA infants demonstrated an appropriate metabolic response to the stress of delivery. The finding on multiple regression analysis of the relationship between the degree of growth retardation and raised nonesterified fatty acids, total gluconeogenic substrate, and lactate concentrations provides further evidence of antenatal stress in growth retarded fetuses.

In contrast, the finding of low cord glucose concentrations in SGA preterm infants, which were correlated with the degree of growth retardation, is in accordance with the work of Soothill et al,${ }^{7}$ Smith et al, ${ }^{9}$ and Economides and Nicolaides, ${ }^{10}$ and suggests that, for preterm infants in this study, intrauterine growth retardation was contributing to metabolic stress in utero.

The finding that infants with clinical evidence of fetal distress did not have significantly lower cord $\mathrm{pH}$ values than infants without fetal distress, but had significantly higher cord blood lactate concentrations, suggests that blood lactate may be a more sensitive marker for fetal distress than cord $\mathrm{pH}$. This calls into question the results of studies which suggest that the principal risk factor for adverse neonatal outcome is cord $\mathrm{pH}^{20}$

The differences found between enteral and intravenous intakes for term SGA and AGA infants probably reflected the additional clinical and nursing attention the former received. In contrast, the lack of differences between preterm AGA and SGA infants may be the result of the close attention paid to the nutrition of all preterm babies, irrespective of their relative size, with uniform policies of early enteral feeding.

There was evidence that the feeding regimens used were effective in maintaining adequate blood glucose concentrations in the SGA infants studied. On each day, the mean blood glucose concentrations were not significantly different for SGA and normal infants.

This is in accord with a recent study by Heck and Erenberg, ${ }^{21}$ and in contrast to older studies that have found low fasting blood glucose concentrations in SGA infants ${ }^{22-24}$ and a high prevalence of hypoglycaemia. ${ }^{6} 25$ These differences in findings are likely to reflect evolutionary changes in clinical management.

There are other aspects of metabolic adaptation that appear to have been affected by intrauterine growth retardation. Low fatty acid and ketone body concentrations have previously been described for SGA infants on the first postnatal day. ${ }^{22} 26$ This is not surprising in the light of our findings that low ketone 
body concentrations are normally found for AGA infants at this age. ${ }^{15}$ Our studies are the first to describe changes in ketone body concentrations with postnatal age in SGA infants.

AGA term infants (more than 1 day old) demonstrated counterregulatory ability by responding to low blood glucose concentrations with increased ketone bodies, particularly high ketone body concentrations being found for 2-3 day old infants. ${ }^{15}$ SGA infants had significantly lower ketone body concentrations than normal infants up to 4 days of age. Taken in isolation, this finding might have been interpreted as demonstrating the suppressive effect on ketone body production of high glucose concentrations. However, the multiple regression analysis findings suggest that blood glucose concentration was a less important factor determining ketone body concentrations than the degree of growth retardation, and the lack of the normal relationship between ketone body and glucose concentrations for term SGA babies strongly suggests that there was a failure of counterregulatory ketogenesis. This may have been secondary to an inability to mobilise nonesterified fatty acids from adipose tissue, to a failure of $\beta$ oxidation of fatty acids, or to a combination of both these factors. The pattern was similar for SGA term babies, 1 day old AGA babies, and preterm babies, which suggests that SGA infants have a persistent immaturity of metabolic response. As with AGA preterm babies, ${ }^{15}$ it appears that enteral feeding of preterm SGA babies may improve ketogenic ability, giving rise to the unexpected positive relationship between enteral feed intake and ketone body concentration. This relationship may reflect the provision in milk of fatty acids or of carnitine, which may enhance fatty acid metabolism in the liver, or a stimulatory effect, via gut hormone secretion, on the hormones and enzymes involved in fatty acid mobilisation and ketogenesis.

High concentrations of gluconeogenic precursors have been reported in studies of SGA infants on the first postnatal day, especially for those who become hypoglycaemic. ${ }^{22}$ 26-28 These studies did not report the subsequent changes in substrate concentrations after the first postnatal day, however, or examine the influence of other factors. Although our data also suggest that gluconeogenesis may have been deficient in SGA infants in the immediate postnatal period, with an accumulation of gluconeogenic precursors, we failed to find a negative relationship between glucose and total gluconeogenic substrate concentrations. This may be because total gluconeogenic substrate concentrations reflect both the processes of release, under the influence of stress hormones, and of utilisation. The high concentrations of gluconeogenic precursors, seen in the present study in the early postnatal period, may have arisen from their release in response to perinatal stress, mediated by the effects of hormones such as catecholamines. After the first postnatal day, these precursor concentrations were low for term SGA infants, which may reflect the adequate provision of energy, enterally or intravenously, so that gluconeogenic precursor release was not stimulated. Turnover studies would be required to elucidate the relationship of substrate utilisation with respect to absolute concentrations.

Previous studies have examined the ability of the MAC:HC ratio to predict metabolic abnormalities in SGA infants. ${ }^{5}$ However, there are no data regarding the effects of both body size and asymmetry of growth retardation of fuels other than glucose. In the present study, the multiple regression analysis findings indicate that both degree of growth retardation, as measured by birthweight SD score, and asymmetry of growth retardation, as measured by MAC:HC, separately affected aspects of postnatal metabolic adaptation. The degree of growth retardation, at term, was the most important determinant of relatively high non-esterified fatty acid concentrations at birth and low ketone body concentrations on the third postnatal day. The more asymmetrical babies, at term, had higher total gluconeogenic substrate at birth and lower nonesterified fatty acids on the third postnatal day. The effects of clinical management in the form of provision of energy, however, overrode these factors on the second postnatal day. For preterm babies, more severe growth retardation was associated with lower cord blood glucose concentrations. We did not find the MAC:HC ratio correlated with blood glucose concentrations at birth, or during the early postnatal period, and suggest that to consider only the effect of brain:body size on glucose concentrations is too simplistic.

This study has demonstrated that changes in blood glucose concentrations provide an inadequate description of the process of metabolic adaptation in SGA infants.

The patterns of metabolic adaptation seen in SGA term infants, with failure of ketogenesis and accumulation of gluconeogenic precursors, were similar to, but more prolonged than those seen in healthy preterm infants; SGA and AGA preterm infants were found to have few significant differences in terms of metabolic adaptation. The process by which preterm and SGA babies eventually acquire mature metabolic responses, and the long term clinical implications of these metabolic differences will only be found by case-control follow up studies. In addition, the role of enteral feeding, and of dietary components such as carnitine, warrant further study.

The failure to utilise gluconeogenic precursors and the failure of ketogenesis are reminders that these SGA infants, especially when very wasted, were unable to respond to low blood glucose concentrations, and these deficiencies persisted for almost all of the first postnatal week. Attention to early enteral and intravenous nutrition of these infants resulted in maintenance of normoglycaemia for the majority of infants. Efforts must continue to prevent severe intrauterine growth retardation and to seek effective means of promoting metabolic adaptation in these infants once they are born. 
Dr Hawdon was supported by the Scientific and Research Committee of Newcastle Health Authority and by a Foundation for the Study of Infant Deaths training fellowship. We thank the parents who gave consent for the inclusion of their babies in the study and acknowledge the assistance of Ms A McGann with metabolite assays.

This work was presented in part at a meeting of the Neonatal Society in February 1991.

1 Cornblath M, Odell GB, Levin EY. Symptomatic neonatal hypoglycemia with toxaemia of pregnancy. $f$ Pediatr hypoglycemia with

2 Neligan GA, Robson E. Watson J. Hypoglycaemia in the newborn. A sequel of intrauterine malnutrition. Lancet 1963;i: 1282

3 Jarai I, Mestyan J, Schultz K, Lazar A, Halasz M, Krassy I. Body size and neonatal hypoglycaemia in intrauterine growth retardation. Early Hum Dev 1977;1:25-38

4 Haworth JC, Dilling L, Younoszai MK. Relation of blood glucose to haematocrit, birthweight and other body measurements in normal and growth retarded newborn infants. Lancet 1967;ii:901-5.

5 Georgieff MK, Sasanow SR, Chockalingam UM, Pereira GR. A comparison of the mid-arm circumference/head circumference ratio and ponderal index for the evaluation of newborn infants after abnormal intrauterine growth. of newborn infants after abnormal

6 Lubchenco LO, Bard H. Incidence of hypoglycemia in newborn infants classified by birth weight and gestational age. Pediatrics $1971 ; 47: 831-8$

7 Soothill PW, Nicolaides KH, Campbell S. Prenatal asphyxia, hyperlacticaemia, hypoglycaemia, and erythroblastosis in growth retarded fetuses. BMF 1987;294:1051-3.

8 Pardi G, Buscaglia M, Ferrazzi E, et al. Cord sampling for the evaluation of oxygenation and acid-base balance in growth retarded human fetuses. Am 7 Obstet Gynecol 1987;157:1221-8.

9 Smith JH, Anand KJS, Cotes PM, et al. Antenatal fetal heart rate variation in relation to the respiratory and metabolic status of the compromised human fetus. $\mathrm{Br} \mathcal{F}$ Obstet Gynaecol 1988; 95:980-9.

10 Economides DL, Nicolaides KH. Blood glucose and oxygen tension levels in small-for-gestational age fetuses. $\mathrm{Am}$ gen tension levels in small-for-gest

11 Usher RH. Clinical and therapeutic aspects of fetal malnutrition. Pediatr Clin North Am 1970;17:169-83.

12 Mestyan J. Energy metabolism and substrate utilisation in the newborn. In: Sinclair JC, ed. Temperature regulation and energy metabolism in the newborn. New York: Grune and Stratton, 1978,39-74.

13 Jones RAK, Robertson NRC. Problems of the small for dates baby. Clin Obstet Gynecol 1984;11:499-524.
14 Hay WW. Fetal and neonatal glucose homeostasis and their relation to the small for gestational age infant. Semin Perinatol 1984;8:101-16.

15 Hawdon JM, Ward Platt MP, Aynsley-Green A. Patterns of metabolic adaptation for preterm and term infants in the first neonatal week. Arch Dis Child 1992; 67:357-65.

16 Neligan GA, Prudham D, Steiner H. Variations in intrauterine growth. In: Neligan GA, Prudham D, Steiner H. The formative years. London: Oxford University Press, 1974 .

17 Sasanow SR, Georgieff MK, Pereira GR. Mid arm circumference and mid arm circumference/head circumference
ratios: standard curves for anthropometric assessment of ratios: standard curves for anthropometric assessment

18 Aynsley-Green A. The control of the adaptation to postnatal nutrition. Monographs in Pediatrics 1982; 16:59-87

19 Lucas A, Morley R, Cole T. Adverse neurodevelopmental outcome of moderate neonatal hypoglycaemia. BMF 1988;297:1304-8.

20 Towell ME. The rationale for biochemical monitoring of the fetus. F Perinat Med 1988;16(suppl 1):55-70.

21 Heck LJ, Erenberg A. Serum glucose levels in term neonates during the first 48 hours of life. $\mathcal{f}$ Pediatr 1987;110:119-22.

22 Haymond MW, Karl IE, Pagliara AS. Increased gluconeogenic substrate in the small for gestational age infant. $N$ Engl f Med 1974;291:322-8.

23 Ogata ES, Bussey ME, Finlay S, La Barbara A. Altered growth, hypoglycemia, hypoalaninemia and ketonemia in the young rat: postnatal consequence of intrauterine growth retardation. Pediatr Res 1985;19:32-7.

24 Levitsky LC, Kimber A, Marchichow JA, Vehara J. Metabolic response to fasting in experimental growth retardation induced by surgical and non-surgical maternal stress. Biol Neonate 1977;31:311-5.

25 Stanley CA, Anday EK, Baker L, Delivoria-Papadopolous $M$. Metabolic fuel and hormone responses to fasting in newborn infants. Pediatrics 1979;64:613-9.

26 Sabel K-G, Olegard R, Mellander M, Hildingsson K. Interrelation between fatty acid oxidation and control of gluconeogenic substrates in small for gestational age gluconeogenic substrates in small for gestational age Acta Paediatr Scand 1982;71:53-61.

27 Linblad BS. The venous plasma free amino acid levels during the first hours of life. I After normal and short gestation complicated by hypertension with special reference to the 'small for dates' syndrome. Acta Paediatr Scand 970;59:13-20.

28 Mestyan J, Soltesz G, Schultz K, Horvath M. Hyperaminoacidaemia due to the accumulation of gluconeogenic amino acid precursors in hypoglycemic small for gestational age infants. $\mathcal{F}$ Pediatr 1975;87:409-14. 